\begin{tabular}{|c|cc|c|}
\hline & \multicolumn{3}{|c|}{ PORT SAID ENGINEERING RESEARCH JOURNAL } \\
\cline { 1 - 3 } & Faculty of Engineering - Port Said University \\
\hline
\end{tabular}

\title{
Biomimicry Levels as an Approach to The Architectural Sustainability
}

\author{
Merhan Mohammed Mohammed Shahda ${ }^{1}$, Ashraf Abd Elfattah Elmokadem ${ }^{2}$ \\ Mostafa Mohammed Abd Elhafeez ${ }^{3}$
}

\begin{abstract}
- What is Biomimicry?

- What are the Biomimicry Levels?

- How can use the Biomimicry to support Architectural sustainability ?????
\end{abstract}

Certainly nature was and still the first teacher to humans and the main inspiration. Nature is a source of inspiration for architects as it is for scientists, for example: its consider source of inspiration for structures, building materials and systems of environmental and aesthetics. There aren't enough studies to conclude and devise solutions from nature to all areas of science and architecture. Branch of knowledge appeared called "Biomimicry" which mean (Nature Simulation) is an innovation method that seeks sustainable solutions by emulating nature's time-tested patterns . In this framework, research paper deals with nature as inspiration concept, Biomimicry concept, Biomimicry levels and approach in the field of architecture and The research presents a number of questions and try to answer them :

Keywords: Biomimicry - Sustainability

\section{INTRODUCTION}

Biomimicry is an innovation method that derives inspiration through the study of natural designs, systems and processes to resolve human problems. Nature can teach us about systems, materials, processes, structures and aesthetics. By studying how nature solves problems which we are facing today, as could be extracted and explored appropriateness solutions and new directions for our built environments.

There are many attempts to achieve sustainability through new designs and ideas or using smart materials and energy-saving. There are many attempts to develop global standards for achieving sustainability, but so far not all truly sustainable architectural practices. According to leading biomimetic thinker Bill Reed1 (who co-chaired the development of LEED standards from the outset), we could "have a world full of LEED platinum buildings and still destroy the planet". These greener designs, though progressive, often stick too close to the existing standard in a way that is simply "less bad". He states that our designs need to be "Regenerative" , meaning that we need to contribute to biodiversity with our own designs [1].

On the way the Search for a solution to the planet problems and what are the best ways to make building designs become part of the ecosystem and not make the building an outsider to the ecosystem, which leads to imbalance in the environment, The research imposes, the simulation of ecosystems and organisms which be a commensally with the environment through time, without any defect and discusses the latest and the best solutions to achieve sustainability. Biomimicry presents a solution to the problems of our environment. Biomimicry is an inspirational source of possible new innovation and because of the potential it offers as a way to create a more regenerative built environment.

\section{NATURE AS INSPIRATION}

Nature is the most important sources of creativity and inspiration in Architecture

\subsection{The natural environment as a source of inspiration for architectural}

There is no doubt That the natural environment is the most important source of inspiration for the creative architect. Whether endless formations or how wonderful adaptation between ecosystems and organisms. In modern times, there is some evidence which refers to inspire some architects for their architectural ideas from the natural environment, comes to the fore, Frank Lloyd Wright, and through the study of the natural environment and laws. He was able to realize how to derive from the environment form structural configuration of the structure of buildings . An example, Frank Lloyd Wright used the structural principles of the mushroom for the design of the interior pillars in the administrative offices of Johnson Wax, Racine, Wisconsin, USA, 1936-1939, [2]. see figure 1 , the idea of spiral ramp in Guggenheim Museum inspired by seashells 1943, see figure 2 .

\footnotetext{
${ }^{1}$ Assistant lecturer in the Architecture and Urban Design Department, Faculty of Engineering, Port Said University

${ }^{2}$ Professor of Architecture and Urban Design Department, Faculty of Engineering, Port Said University .

${ }^{3}$ Professor and Head of Architecture and Urban Design Department, Faculty of Engineering, Port Said University .
} 


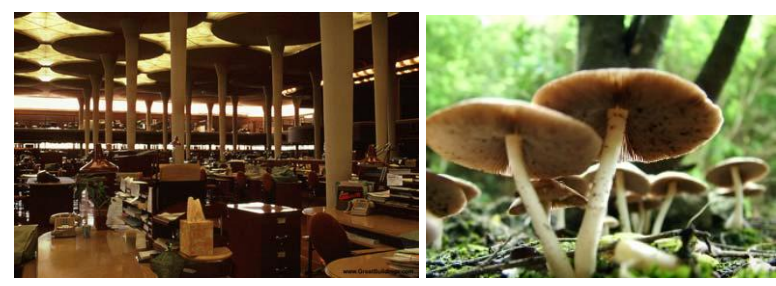

Figure 1: Hall staff in the administrative building of Johnson - design "Wright"1936 [3]

Figure1 shows the idea of a column widespread header that Wright inspired from mushroom.
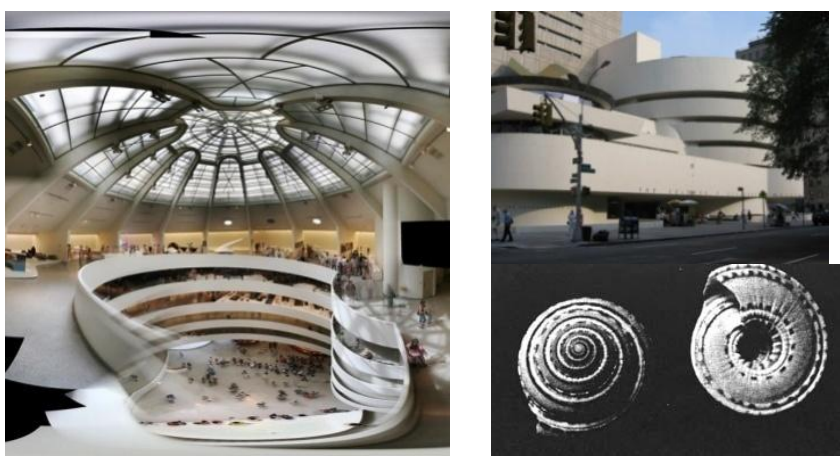

Figure 2:Upward spiral ramp at the Guggenheim Museum - Design "Wright"[4]

Figure 2 shows upward spiral ramp idea that inspired the "Wright" from the shell.

\subsection{Methods of dealing with the sources of creativity}

A. copying: such as imaging

B. Abstraction: is innovation, a hierarchical form is a abstraction of the mountain

C. inspiration: reflects the creative ability to create the principles of composition, for instance shells construction inspired by seashells

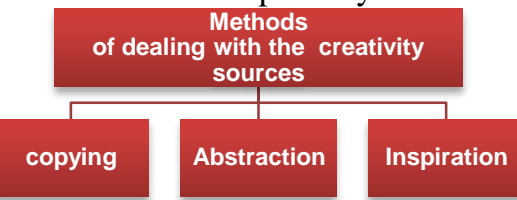

Figure 3: Methods of dealing with the creativity sources

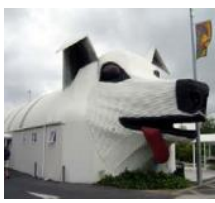

A

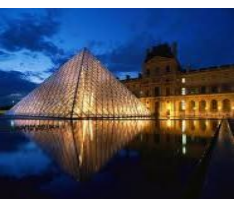

B

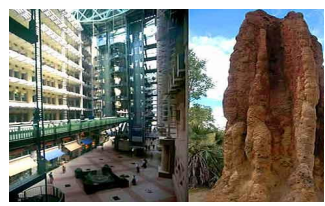

C
Figure 4 : comparison between Methods of dealing with the creativity sources

\section{WHAT IS BIOMIMICRY?}

Biomimetics and Biomimicry are both aimed at solving problems by first examining, and then imitating or drawing inspiration from models in nature.

Biomimetics is the term used to describe the substances, equipment, mechanisms and systems by humans to imitate natural systems and designs.
Biomimicry is an innovation method that seeks sustainable solutions by emulating nature's time-tested patterns and strategies, e.g., a solar cell inspired by a leaf. The goal is to create products, processes, and policies--new ways of living---that are well-adapted to life on earth over the long haul ., biomimicry has gained prominence as a method to reduce human's impact on our environment since Janine Benyus, a biological science writer, gave name and purpose to this innovative concept [5].

"Nature is my mentor for business and design, a model for the way of life. Nature's system has worked for millions of years... Biomimicry is a way of learning from nature."[6].

\section{THE BIOMIMICRY APPROACHES}

Biomimicry moves our present day ideology closer to nature by using nature as a design inspiration to sustainably solve human problems. Biomimicry links the built environment to the natural world by striving to use Mother Nature as a model, a standard of measure, and a mentor, see figure 4 . The rationale for this approach is that "the more our world looks and functions like this natural world, the more likely we are to be accepted on this home that is ours, but not ours alone [7] .

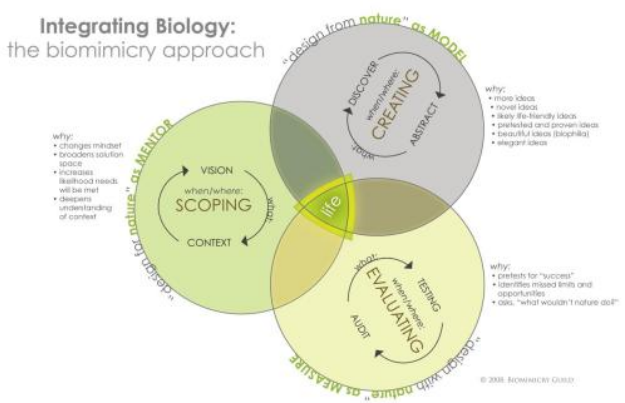

Figure 5 : Viewing nature as a design model, measure, and mentor[8]

Table 1: comparison between nature as a model, measure, and mentor

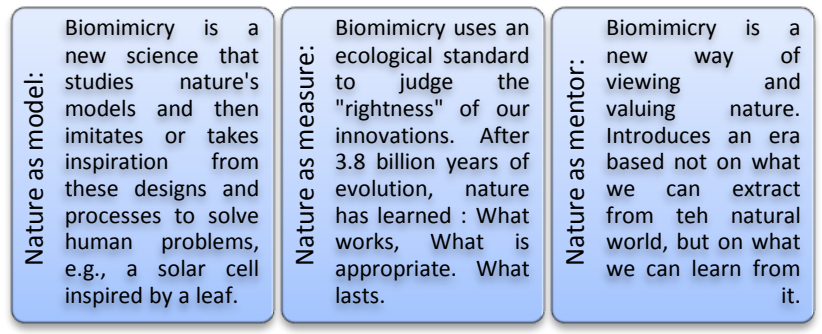

Approaches to Biomimicry as a design process typically fall into two categories: Defining a human needs or design problem and looking for the ways other organisms or ecosystems solve this, termed here design looking to biology, or identifying a particular characteristic, behaviour or function in an organism or ecosystem and translating that into human designs, referred to as biology influencing design [9]. 


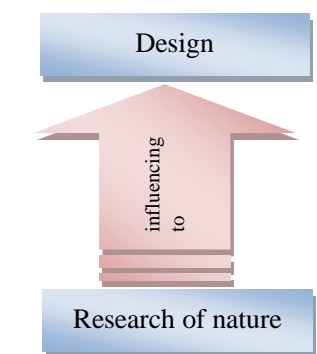

Discover exploits in solving the problems around us

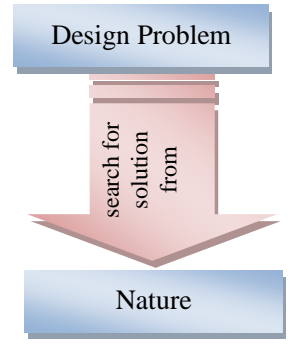

I have a problem Search in nature for solutions
Figure 6: comparison between biomimicry approaches

\subsection{Design looking to biology}

The approach where designers look to the living world for solutions, requires the designers to identify problems and biologists to match these to organisms that have solved similar issues. This approach is effectively led by designers identifying initial goals and parameters for the design.

An example of such an approach is:

\subsubsection{A Robotic Arm Inspired by the Elephant's Trunk}

As scientists tried to design a robotic arm, one of the worst problems they faced was achieving freedom of movement. In order for a robot's arm to serve any useful purpose, it must be able to perform all the movements required by that particular task. In nature, God has created all creatures with the ability to move their limbs in such a way as to meet all their needs. An elephant's trunk, with its 50,000 or so muscles, 135 is one of the most striking examples. ,The elephant is able to move its trunk in any direction it wants and can perform tasks requiring the greatest care and sensitivity. ,One robotic arm constructed in the U.S. at Rice University clearly reveals the elephant trunk's superior design. There is no single skeleton-like structure in the trunk, thus endowing it with enormous flexibility and lightness. The robotic arm, on the other hand, has a spine. The elephant's trunk possesses a degree of movement which allows it to move in any direction, while the robotic arm is comprised of 32 degrees of freedom in 16 links. This only goes to show that the elephant trunk is a special structure, whose every particular feature reveals the nature of God's flawless art in creation [5].
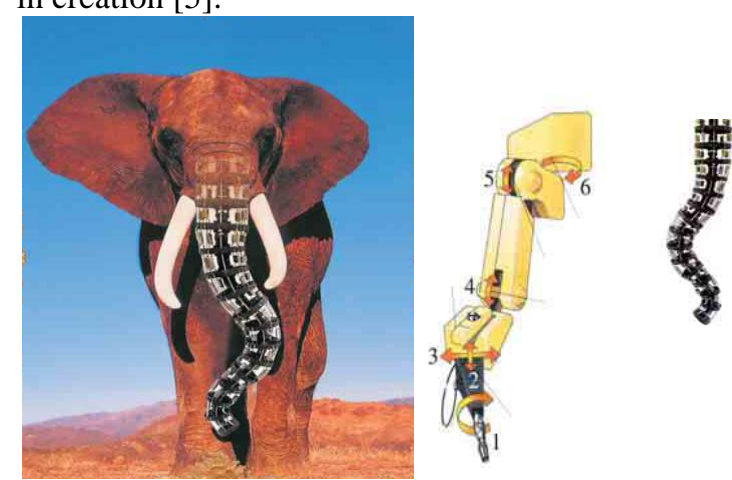

Figure 7: A Robotic Arm Inspired by the Elephant's Trunk

\subsubsection{Steel-Cable Technology in Muscles}

Tendons, These tissues which connect muscles to the bones, have a very firm yet pliant structure, thanks to the collagen-based fibers that make them up. Another feature of tendons is the way their fibers are woven together., Ms. Benyus is a member of the teaching faculty at America's Rutgers University. In her book Biomimicry, she states that the tendons in our muscles are constructed according to a very special method and goes on to say: The tendon in your forearm is a twisted bundle of cables, like the cables used in a suspension bridge. Each individual cable is itself a twisted bundle of thinner cables., the steel-cable technology used in present-day suspension bridges was inspired by the structure of tendons in the human body. The tendons' incomparable design is only one of the countless proofs of God's superior design and infinite knowledge [7].

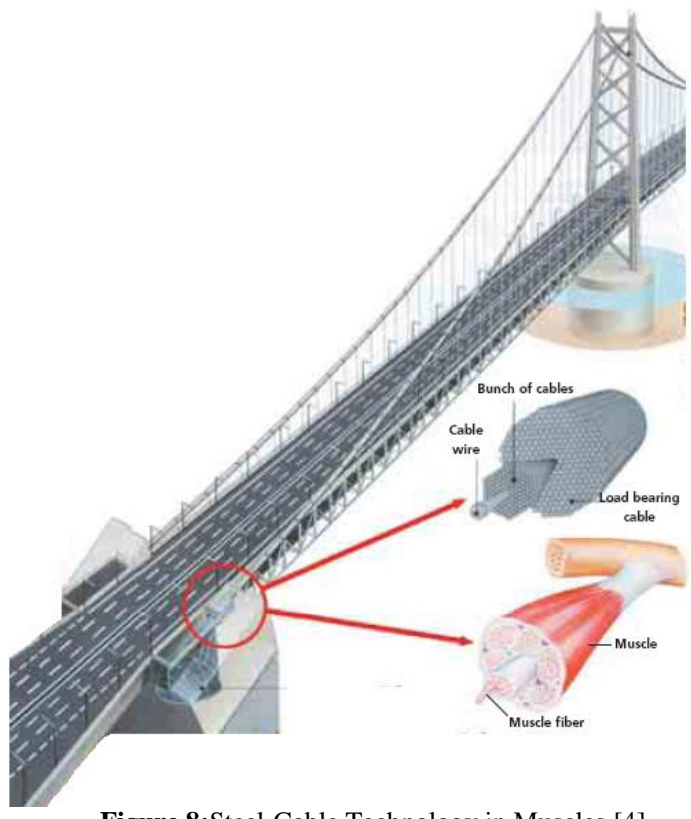

Figure 8: Steel-Cable Technology in Muscles [4]

The Biomimicry Institute has referred to this design approach and explained it through the Challenge to Biology Design Spiral as illustrated in figure 9. Research held in Georgia Institute of Technology at the Design Intelligence Lab in 2006, also defined this approach through 6 definite steps, which are very similar to those defined by the Biomimicry Institute:

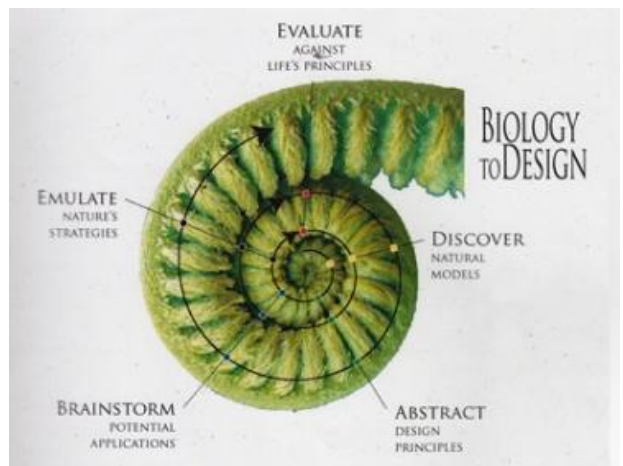

Figure 9: Design Spiral by the Biomimicry Institute [10] 
- Step 1: problem definition

- Step 2: reframe the problem

- Step 3: biological solution search

- Step 4: define the biological solution

- Step 5: principle extraction

- Step 6: principle application

\subsection{BIOLOGY INFLUENCING DESIGN}

When biological knowledge influences human design, the collaborative design process is initially dependant on people having knowledge of relevant biological or ecological research rather than on determined human design problems.

An example of such an approach is:

\subsubsection{The Constantly Self-Cleaning Lotus}

The lotus plant (a white water lily) grows in the dirty, muddy bottom of lakes and ponds, yet despite this, its leaves are always clean. That is because whenever the smallest particle of dust lands on the plant, it immediately waves the leaf, directing the dust particles to one particular spot. Raindrops falling on the leaves are sent to that same place, to thus wash the dirt away. This property of the lotus led researchers to design a new house paint. Researchers began working on how to develop paints that wash clean in the rain, in much the same way as lotus leaves do. As a result of this investigation, a German company called ISPO produced a house paint brand-named Lotusan. On the market in Europe and Asia, the product even came with a guarantee that it would stay clean for five years without detergents or sandblasting [11].

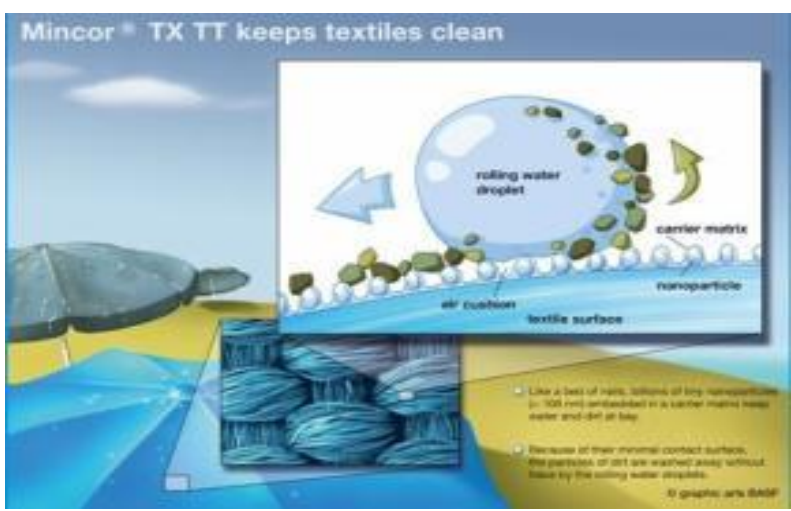

Figure 10: The Constantly Self-Cleaning Lotus

\subsubsection{Butterfly wings and solar cells.}

The butterfly wings have scales that act as tiny solar collectors has led scientists in China and Japan to design a more efficient solar cell that could be used for powering. The researchers turned to the microscopic solar scales on butterfly wings in their search for improvements. Using natural butterfly wings as a mold or template, they made copies of the solar collectors and transferred those light-harvesting structures to Grätzel cells. Laboratory tests showed that the butterfly wing solar collector absorbed light more efficiently than conventional dye-sensitized cells [12].

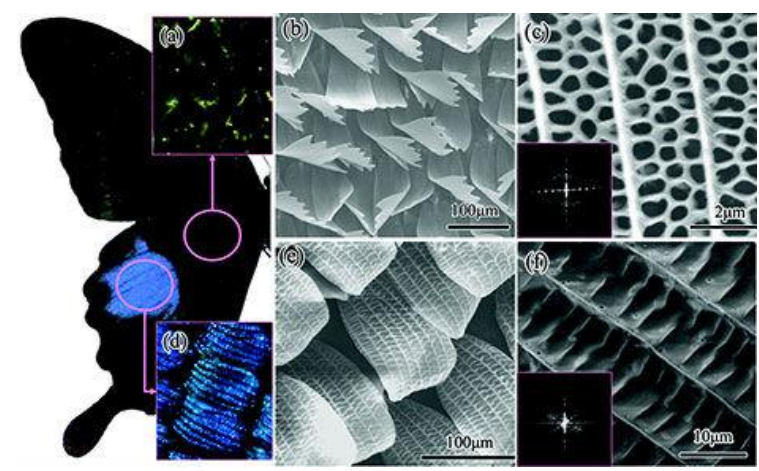

Figure 11: Butterfly wings and solar cells.

A disadvantage from a design point of view with this approach is that biological research must be conducted and then identified as relevant to a design context. Biologists and ecologists must therefore be able to recognize the potential of their research in the creation of novel applications. , Research held in Georgia Institute of Technology by defined this approach through 7 definite steps:

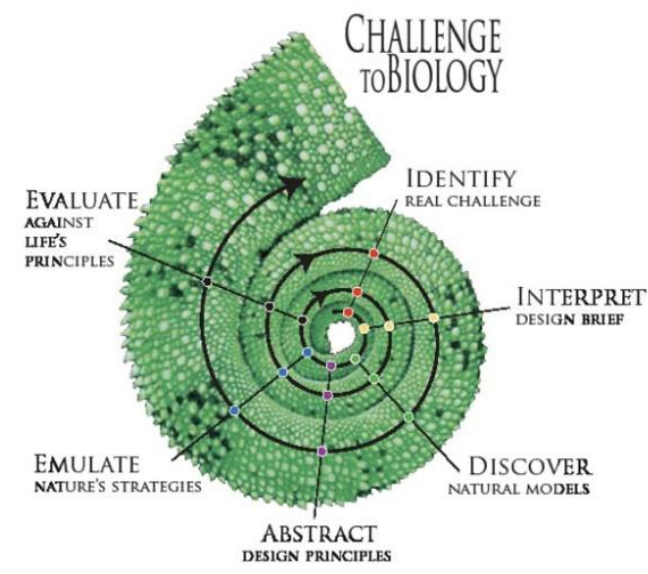

Figure 12: The Challenge to Biology Design Spiral, [13].

- Step 1: biological solution identification

Here, designers start with a particular biological solution in mind.

- Step 2: define the biological solution.

- Step 3: principle extraction.

- Step 4: reframe the solution.

In this stage, reframing forces designers to think in terms of how humans might view the usefulness of the biological function being achieved.

- Step 5: problem search.

Whereas search in the biological domain includes search through some finite space of documented biological solutions, problem search may include defining entirely new problems. This is much different than the solution search step in the problem-driven process.

- Step 6: problem definition.

- Step 7: principle application.

\section{LEVELS OF (BIOMIMICRY).}

There are three levels of Biomimicry; Nature is the inspiration for the formation, Mimicry of how an organism behaves and ecosystem. The first level refers 
to a specific organism like a plant or animal and may involve mimicking part of or the whole organism. The second level refers to mimicking behaviour, and may include translating an aspect of how an organism behaves, or relates to a larger context. The third level is the mimicking of whole ecosystems and the common principles that allow them to successfully function.
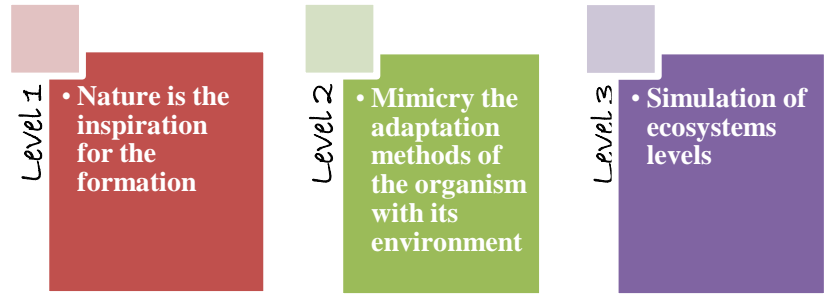

Figure 13: Levels of Biomimicry

\subsection{The first level: Nature is the inspiration for the formation .}

God created nature in a comprehensive picture of a rich and varied forms, this forms success to withstand in the environment Although the different circumstances, Architects and Structural inspired from nature formations for many of the structural systems, as shown by the following examples:

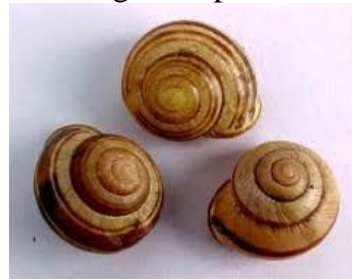

Figure 14: Inspired from the shells the system of shell Construction

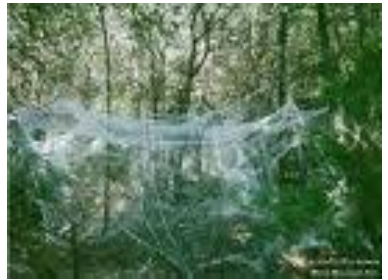

Figure 15:stretched cables from the spider net

\subsection{The Second level : Mimicry of how an organism behaves .}

A great number of organisms facing the same environmental conditions that humans face, but these organisms try to solve their problems within limits of energy and material availability, and continue to development the solutions even with the change of the Challenges of the around environmental conditions .

In behaviour level Biomimicry, it is not the organism itself that is mimicked, but its behaviour. It may be possible to mimic the relationships between organisms or species in a similar way. An architectural example of process and function Biomimicry at the behaviour level is demonstrated by Mick Pearce's Eastgate Building in Harare, Zimbabwe and the $\mathrm{CH} 2$ Building in Melbourne, Australia, see figure 16. Both buildings are based in part on techniques of passive ventilation and temperature regulation observed in termite mounds, in order to create a thermally stable interior environment. Water which is mined (and cleaned) from the sewers beneath the $\mathrm{CH} 2$ Building is used in a similar manner to how certain termite species will use the proximity of aquifer water as an evaporative cooling mechanism [12].

\subsection{Third level : Ecosystem Level}

The mimicking of ecosystems is an integral part of bio-mimicry, the term eco-mimicry has also been used to describe the mimicking of ecosystems in design also uses the term to mean a sustainable ,the advantage of

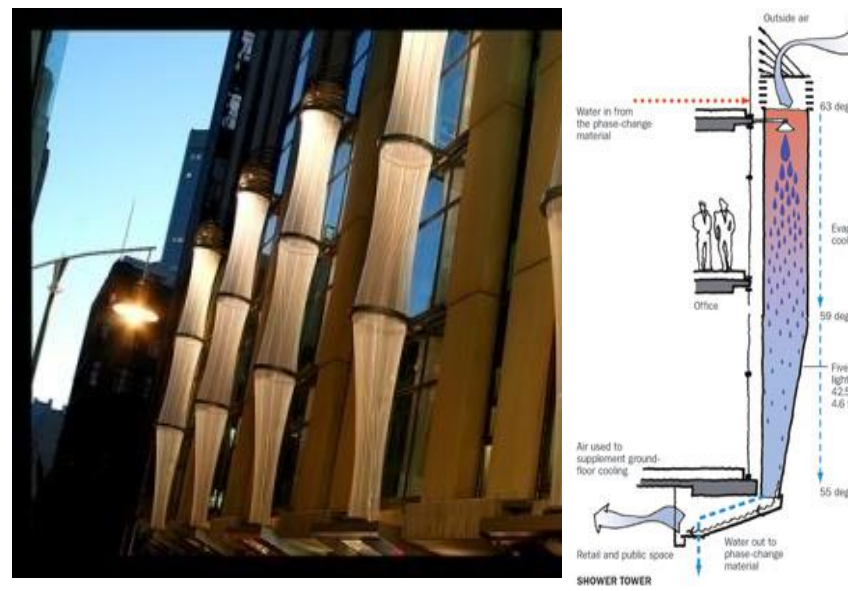

Figure 16:Council House Two (CH2), Melbourne designing at this level of bio-mimicry is that it can be used in conjunction with other levels of bio-mimicry (organism and behaviour). beside the principles of sustainable.

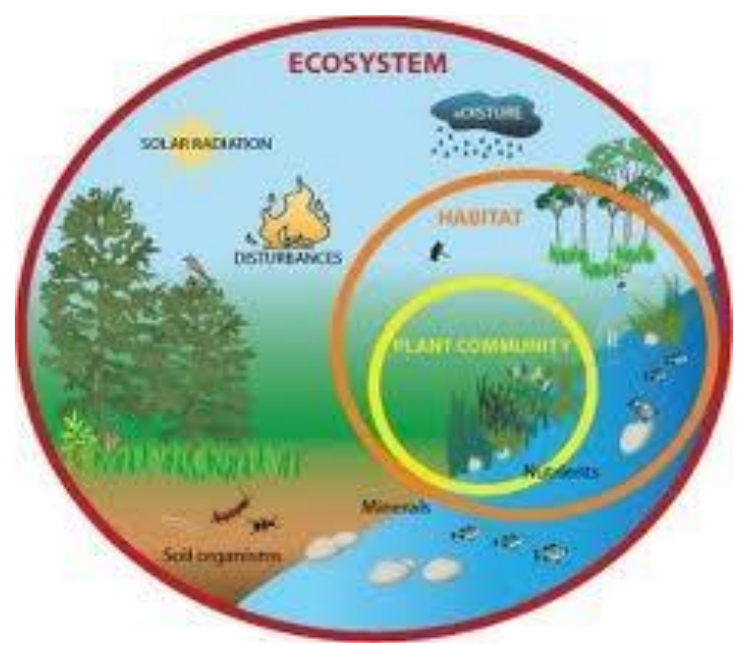

Figure 17: Ecosystem Level Closed circle

Ecosystem principles can be defined as follows [13]:

- Ecosystems are dependent on contemporary sunlight.

- Ecosystems optimize the system rather than its components.

- Ecosystems are attuned to and dependant on local conditions.

- Ecosystems are diverse in components, relationships and information.

- Ecosystems create conditions favorable to sustained life.

- Ecosystems adapt and evolve at different levels and at different rates.

The characteristic of ecosystems being regenerative was a powerful driver for the team to strive for solutions that went beyond 'sustainable' to 'restorative'. The latter point was taken further with an in depth comparison of conventional human-made systems and ecosystems which revealed the following contrasts, at table 2 . 
Table2: comparison of conventional human-made systems and ecosystems [14].

\begin{tabular}{ll} 
Human-made systems & \multicolumn{1}{c}{ Biological systems } \\
\hline Simple & Complex \\
\hline Linear flows of resources & Densely interconnected and symbiotic \\
\hline Disconnected and mono-functional & Adapted to constant change \\
\hline Resistant to change & Zero waste \\
\hline Wasteful & No long-term toxins used \\
\hline Long-term toxins frequently used & Distributed and diverse \\
\hline Often centralised and mono-cultural & Run on current solar income \\
\hline Fossil-fuel dependent & Optimised as a whole system \\
\hline Engineered to maximise one goal & Regenerative \\
\hline Extractive & Use local resources \\
\hline Use global resources
\end{tabular}

\section{HOW CAN USE THE BIOMIMICRY TO SUPPORT ARCHITECTURAL SUSTAINABILITY ?}

From previous studies as a source of inspiration from nature and levels of imitating nature, we can say that each level of imitating nature can solve significant architectural and environmental problems, as shown by the following examples:

\subsection{The First Level : Nature is the inspiration for the formation .}

\subsubsection{Bird's Nest Stadium In China :}

Project Description: The Swiss office "Her Zog et De Mevron" developed the Bird's Nest Stadium together with the Chinese government. The stadium took this name because the iron bars are like a bird's nest. It was designed by simulating birds' shelters which consist of organic material such as branches and grass. The structure of the Bird's Nest is innovated on the grounds of structural systems and the way of how to distribute loads. Designers of the Bird's Nest used the simulation technique (CFD) so as to simulate temperatures, wind power, and humidity inside the structure of birds' nests, and to give the audience the opportunity to enjoy light [15].

\section{The Success of Design in Achieving}

\section{Sustainability :}

- The use of simulation in designing the Bird's Nest to develop a strong structural system.

- Unique architectural formation which achieved aesthetic values Moreover, not to ignore simulating natural ventilation and lighting systems helped to rationalization of energy, This in turn helped in reducing operating costs.

- Reducing pollution emitted from the building as a result of the rationalization of energy consumption.

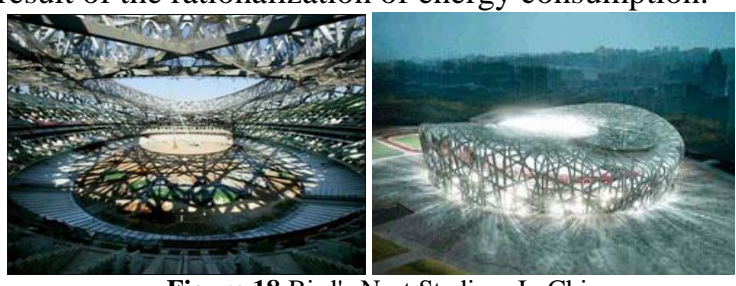

Figure 18:Bird's Nest Stadium In China

\subsubsection{Water cube National Swimming Centre :}

Project Description: The idea of the project is based on soap bubbles. The architects emulated the random appearance of clinging soap bubbles with each other, by making organized models taking the form of cells with 12 through 14 facets. The project consists of $100,000 \mathrm{~m}$ of ETFE bubbles. The fluoropolymer is plastic material which has several advantages [16]:

- It weighs one tenth of glass.

- It is more flexible and transparent.

- It allows passing a larger amount of light.

- It is an excellent insulator. So it saves more than $50 \%$ of lightening costs.

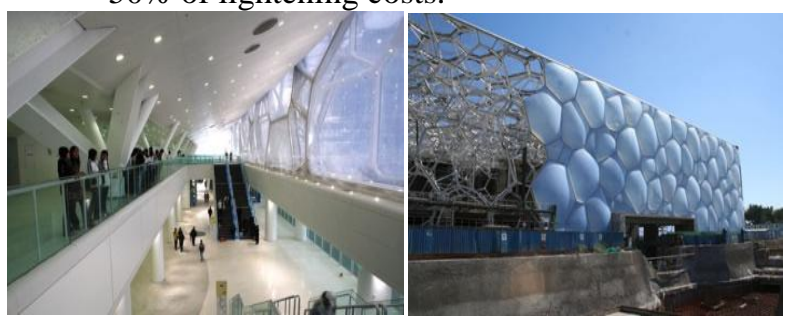

Figure 19: Water cube“ National Swimming Centre

\section{The Success of Design in Achieving} Sustainability :

- Simulating the form and clinging bubbles with each other enriched the architectural formation of the building, which bestowed aesthetic values.

- The up-to-date technology and computer technology which was used in manufacturing and cutting ETFE didn't waste time, manufacture costs, or materials. They could cut 3500 pads to fit their place well, and they had to make just one pad.

- Simulation bubbles transparent appearance with the use of the transparent ETFE with its advantages saved the costs of lightening, and helped with the rationalization of energy.

\subsection{The Second Level : Mimicry of how an organism behaves .}

\subsubsection{Hydrological Center Project}

Project Description: The project is inspired by the Namibian beetle's ability to capture fog to quench its thirst. The beetle's behaviour has been developed in designing the project, was designed to pick water from fog over the building roof to provide all the building needs of water. needs of water [17]. 

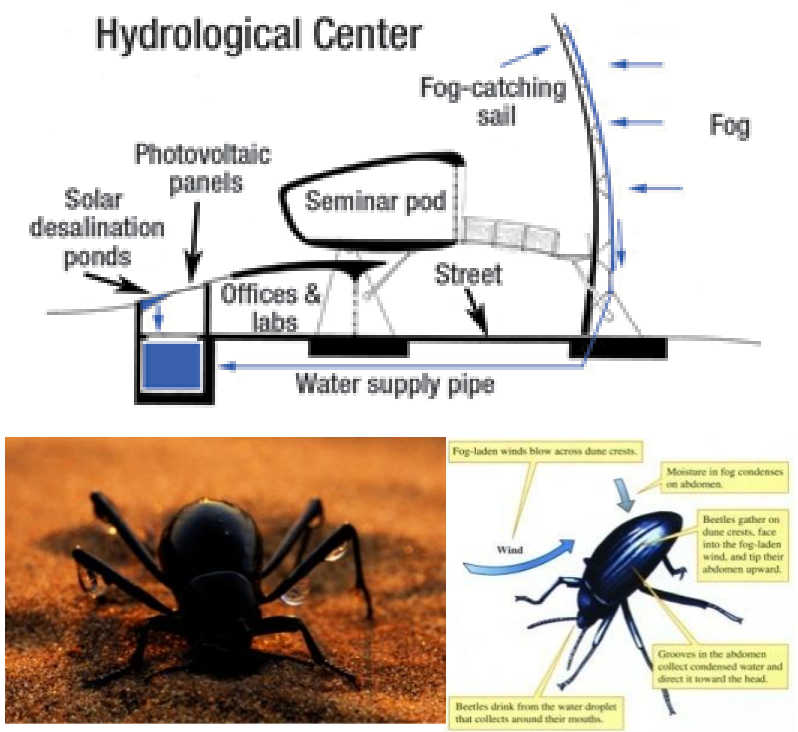

Figure 20:Fog harvesting by a desert beetle [18]

\section{The Success of Design in Achieving \\ Sustainability :}

- The project succeeded through simulating the beetle's behavior toward compatibility with the surrounding environment where fog was heavy.

- Reducing operating costs by provide all the building needs of water.

\subsubsection{East Gate}

Project Description: East Gate designed by the architectural Mick Pace, simulation of termites mounds by using the negative Ventilation technology and control the temperature and create thermal stable environment., Termites in Zimbabwe build mounds that must be kept at exactly $87^{\circ} \mathrm{F}$, while the temperatures outside range from $35^{\circ} \mathrm{F}$ at night to $104{ }^{\circ} \mathrm{F}$ during the day. The termites

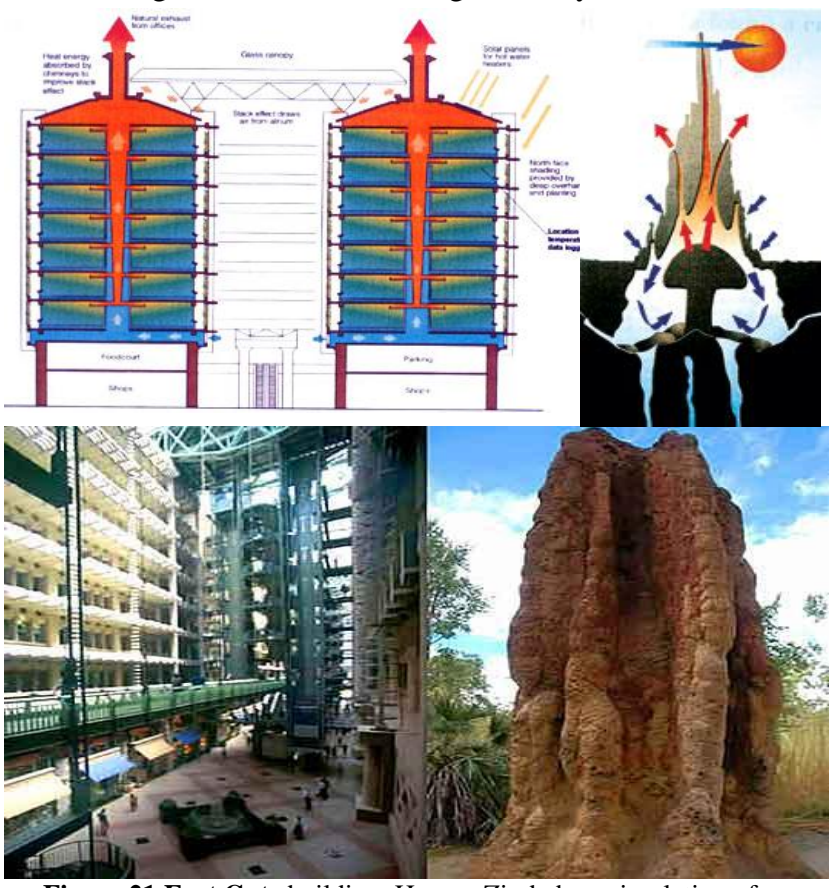

Figure 21:East Gate building, Harare, Zimbabwe simulation of termites mounds. achieve this remarkable feat by constantly opening and closing a series of heating and cooling vents throughout the mound over the course of the day., East Gate building which designed by the architectural Mick Pace Simulator for termites mounds, consume energy less than $10 \%$ than traditional building, which make the rent reduce by $20 \%$ than around building

Mick Pearce says during an interview- ( Mick, Principal Design Architect, City of Melbourne, CH2 Design Team, 2004)-"I funnily enough spent a lot of time studying termite nests and the reason for that is that they're very much cleverer than we are at manipulating the natural environment. These great mounds that they build in nature, aren't like the castles we build to show off, they're actually lungs. The purpose of them is to extend the organism. The organism is the whole termitery ... and the termites are in fact like blood moving around in it. So they build these mounds and they breathe. They actually allow transference of air, and/or gases through a membrane, which is porous and you can study it from the point of view of diffusion of gases. There's quite a lot of science that we've done that would apply to a termitery.' [19].

\subsection{The Third Level : Ecosystem Level}

\subsubsection{California Academy of Sciences museum}

\section{Green Roof}

Project Description: The building received a platinum rating scale "leed", Building designed by the architectural "Renzo Piano" One of the key features of the museum will be an undulating green roof that will mimic the sloping lines of the surrounding landscape. Part of the roof will be accessible to visitors.,- The new Academy building will house an aquarium, planetarium, and exhibition spaces, and is set to open in 2008. Aside from its green roof, the building is a feat of institutional green building, using some of the most cutting-edge energy efficiency strategies, day lighting, possible biofuels, and water reclamation.
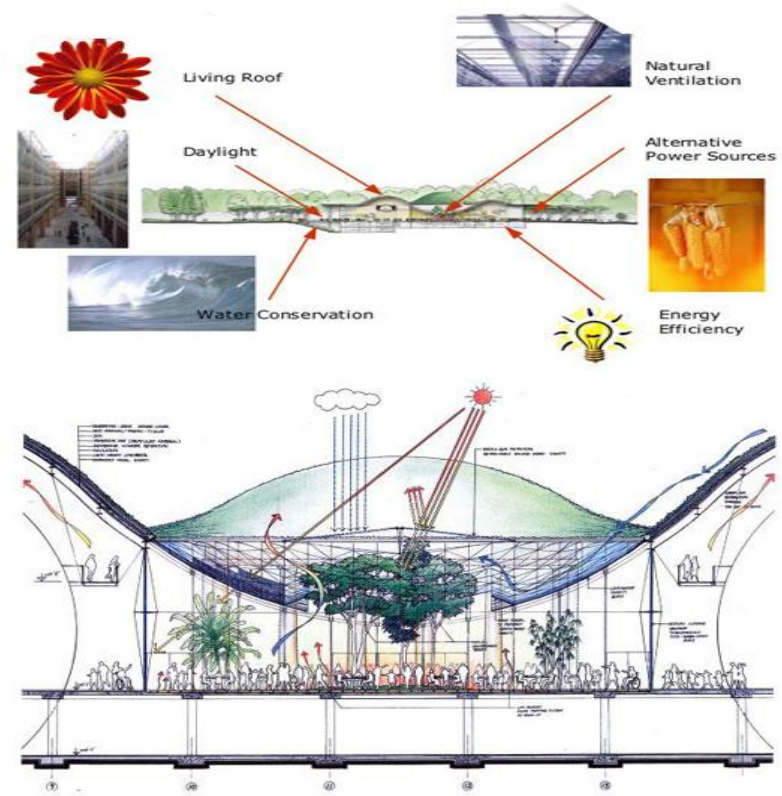

Figure 22: California Academy of Sciences museum Green Roof [20]. 


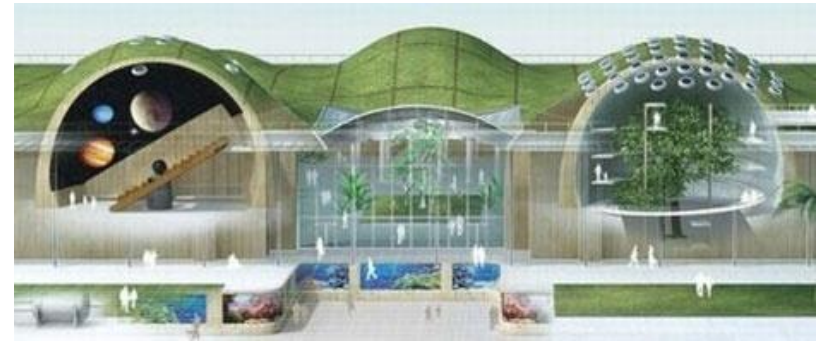

Figure 22: California Academy of Sciences museum Green Roof The Success of Design in Achieving Sustainability :

- The roof itself is estimated to prevent approximately two million gallons of rainwater from becoming storm-water runoff, Storage system of ice for cooling , Agriculture Inclined plane without slid, took a patent called "biotray".

- Plants convert carbon dioxide into oxygen.

- On the roof, stations to monitor the changes of air temperature, wind, rain and inform the negative automated system to ventilation.

\subsubsection{Dome of the German Parliament :}

The German Parliament building connects between originality and modernity. The old building was designed in 1894. A worldwide competition was held by the architect Norman Foster with the purpose of designing an unprecedented dome .giant transparent dome with slopes for getting audience's sights, inverted glass cone reflecting Lighting from sky to the hall

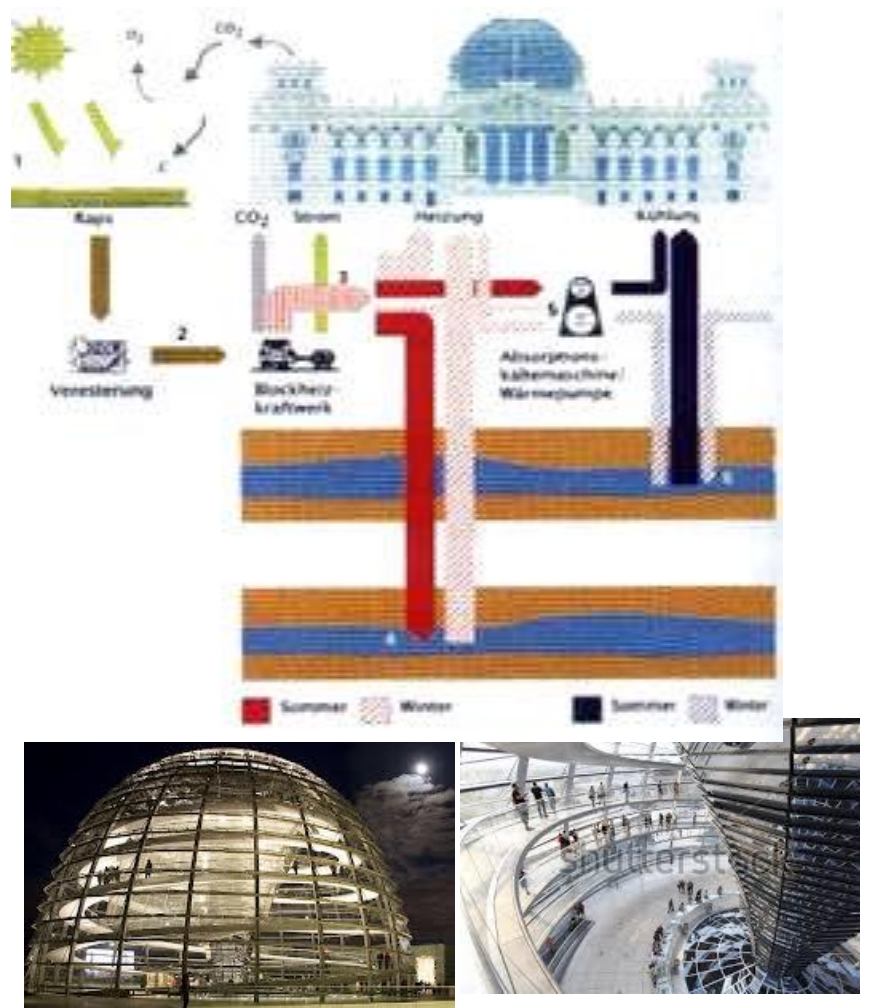

Figure 23: Dome of the German Parliament [21],[22].

\section{The Success of Design in Achieving}

\section{Sustainability :}

The building is based on :

- Aquifer layer: to store coolness for use in Summer.

- lake 300 meters underground : to store heat for use in Winter. This reduced the consumption of nonrenewable energy.

- The use of solar cells and vegetable oil in fueling power generators, reduced $\mathrm{C} 02$ emission.

- All these processing led to reducing the quantity of emission of C02 from 7,000 tons in 1960 to 440 tons currently..

\section{Results and Discussions}

Nature is the most important teacher, can teach us about systems, materials, processes, structures and aesthetics .

- Biomimicry can become a mean for the integration of architecture product with the environment, Besides the attempts to preserve the environment by rationalization of energy resources and reduce pollution to become part of the architectural product of the ecosystem of the environment. .

- Biomimicry can be a tool To become the architecture product Part of the ecosystem of the environment "Closed circle".

- Second approach needs to be a major scientific research team with different specialties and great potential to analyze Ecosystems and organisms behaviors adapted to the environment in closed circles without defects one of the systems and try to drop this on the man problems and society. ,The first approach fits more architect who owns description to the problem of architectural, environmental, construction and looking in nature for solution.

- There is no Enough studies to a conclusion and devise solutions from Nature.

- Attention to Biomimicry not only to search for new sources of inspiration form But also to find new ways of building, The results of this trend is highefficient buildings, sustainability and the rationalization of the energy and materials .

- By use Biomimicry can design whole cities operating like complex ecosystems, processing water and waste while generating energy. Communities in desert regions will be designed to maximize the ability to collect water, like the plants of the desert retain and conserve that water.

\section{References}

[1] Lecture Notes: Biomimicry in Architecture, Retrieved October,12,2013 from the world wide web,http://www.worldchanging.com/local/seattl e/archives/008117.html

[2] Senosiain, Javier, 2003, Bio-architecture, Architectural Press: Oxford and Harmondsworth.

[3] Nouby Mohamed Hasan, May 2005, Inspiration in Architecture: Towards Simplicity and 
Comprehension, Scientific Journal of King Saud University, Architecture and Planning Department, Volume 19, Issue 1.

[4] Designs, Retrieved October,12,2013 from the world wide web, http://www.bokra.net/Articles/1107757/.html

[5] YAHYA HARUN, BIOMIMETICS: Technology Imitates Nature, Retrieved October,12,2013 from the world wide web,http://harunyahya.com/en/Books/3864/bio mimetics-technology-imitates-nature

[6] "Biomimicry," Buckminster Fuller Institute; Retrieved October,12,2013 from the world wide web,http://www.bfi.org/Trimtab/spring01/biomi micry.htm

[7] Benyus, J. M. (1998). Biomimicry: Innovation Inspired by Nature. Perennial (HarperCollins).

[8] Curricula. (2009). Biomimicry Institute.

Retrieved from,

http://www.biomimicryinstitute.org/education/u niversity/curricula.html

[9] Guild, B. (2007). Innovation inspired by nature work book. Biomimicry Guild.

[10] wordpress.com , Retrieved October,12,2013

from the world wide web,

http://biologytodesign.files.wordpress.com/2011 /09/biology-to-design-spiral-sm.jpg

[11] Jim Robbins, "Engineers Ask Nature for Design Advice," New York Times, December 11, 2001.

[12] http://www.treehugger.com/naturalsciences/biomimicry-breakthrough-butterflywings-could-lead-to-better-solar-panels.html

[13]Zari, M. P. (2007). Biomimetic Approaches to Architectural Design for Increased Sustainability. Sustainable Building Conference. Auckland: [Personal communication].

[14]Biomimicry, Retrieved October,12,2013 from the world wide web, http://saharaforestproject.com/concept/biomimic ry.html

[15] 13 THE BEIJING NATIONAL STADIUM SPECIAL ISSUE ,The Arup Journal,1/2009, Retrieved October,12,2013 from the world wide web,www.arup.com/ /media/.../Arup_Journal_1 -2009.ashx

[16] National Aquatics Center (Water Cube), Retrieved October,12,2013 from the world wide web

http://www.arup.com/Projects/Chinese_National Aquatics_Center/Details.aspx

[17] Designers Begin To Look to Nature To Render Buildings in Harmony with the Planet, special theme issue, 2/12/2007, http://enr.construction.com/features/buildings/ar chives/070212f-1.asp

[18] Chapter 5 Water Relations, Retrieved October,12,2013 from the world wide web, http://sky.scnu.edu.cn/life/class/ecology/chapter /Chapter5.htm
[19] (Interview with Mick Pearce, Principal Design Architect, City of Melbourne, CH2 Design Team, 2004) Source: Radovic, D., Crist, G. Technical Research Paper 01, Nature and Aesthetics in the Sustainable City City of Melbourne

[20] California Academy of Sciences Retrieved October,12,2013 from the world wide web,http://inhabitat.com/the-new-californiaacademy-of-sciences/

[21]Berlin , Berlin Attractions , Reichstag, Retrieved October,12,2013 from the world wide web,http://www.aviewoncities.com/berlin/reichs tag.htm

[22] A Smooth Ride With Solar Energy, Retrieved October,12,2013 from the world wide web http://www.dw.de/a-smooth-ride-with-solarenergy/a-1222427-1 